\title{
BMJ Open Health care utilisation preceding relapse or second malignant neoplasm after childhood acute lymphoblastic leukaemia: a population-based matched cohort study
}

\author{
Karen Schow Jensen (D) , ${ }^{1}$ Birgitte Klug Albertsen, ${ }^{1}$ Henrik Schrøder, ${ }^{1}$ \\ Alina Zalounina Falborg, ${ }^{2}$ Kjeld Schmiegelow, ${ }^{3,4}$ Steen Rosthøj, ${ }^{5}$ \\ Michael Thude Callesen, ${ }^{6}$ Peter Vedsted ${ }^{2}$
}

To cite: Jensen KS, Klug Albertsen B, Schrøder H, et al. Health care utilisation preceding relapse or second malignant neoplasm after childhood acute lymphoblastic leukaemia: a population-based matched cohort study. BMJ Open 2021;11:e050285. doi:10.1136/ bmjopen-2021-050285

- Prepublication history and additional supplemental material for this paper are available online. To view these files, please visit the journal online. (http://dx.doi.org/10.1136/ bmjopen-2021-050285).

Received 15 February 2021 Accepted 30 July 2021
Check for updates

(C) Author(s) (or their employer(s)) 2021. Re-use permitted under CC BY-NC. No commercial re-use. See rights and permissions. Published by BMJ.

For numbered affiliations see end of article.

Correspondence to Ms Karen Schow Jensen; kascje@rm.dk

\section{ABSTRACT}

Objectives To investigate health care utilisation including both primary and secondary health care 6 months before the diagnosis of a relapse or a second malignant neoplasm (SMN) in survivors of childhood acute lymphoblastic leukaemia (ALL).

Design and setting $A$ Danish population-based matched cohort study linking multiple nationwide registries.

Participants Participants were recruited from a total of 622 childhood ALL 2.5-year event-free survivors diagnosed between 1994 and 2015. Cases were survivors developing a relapse or an SMN and references were survivors still in first remission. Each case was matched with five references on age, sex, treatment protocol and risk group.

Primary outcome measures Consultations in general practice and hospital the last 6 months before relapse or SMN. Cases and references were compared with monthly incidence rate ratios (IRRs) from negative binomial regression models.

Results Of the 622 childhood ALL survivors, 60 (9.6\%) developed a relapse (49) or an SMN (11) and 295 matched references were identified. Health care utilisation in general practice increased among cases the last month before the event compared with references with an IRR of 2.71 (95\% Cl 1.71 to 4.28 ). Data showed a bimodal structure with a significantly increased number of visits 4, 5 and 6 months before the event. Hospital health care utilisation increased 2 months before the event in cases with an IRR of 5.01 (3.78 to 6.63) the last month before the event and an IRR of 1.94 (1.32 to 2.85) the second-last month comparing cases and references.

Conclusions Survivors of childhood ALL developing a relapse or an SMN have a short period of increased health care utilisation before diagnosis. At hospital, this might be explained by pre-diagnostic examinations. In general practice, data suggest a bimodal structure with children later developing a relapse having more contacts also half a year before the relapse, suggesting that there could be early warnings.

\section{STRENGTHS AND LIMITATIONS OF THIS STUDY}

$\Rightarrow$ The first study to investigate health care utilisation before a relapse or a second malignant neoplasm in survivors of childhood acute lymphoblastic leukaemia.

$\Rightarrow$ Use of complete nationwide registries with nearly no loss to follow-up linked on an individual level ensured that the study was population- based, thus limiting selection bias.

$\Rightarrow$ Outcome data are collected routinely and uniformly in the Danish healthcare system and potential misclassification is thus expected to be non-differential.

$\Rightarrow A$ small case group, leading to low statistical precision.

$\Rightarrow$ Unmeasured confounding could be present.

\section{INTRODUCTION}

Five-year survival from childhood acute lymphoblastic leukaemia (ALL) now exceeds $90 \%$ with an event-free 5-year survival of around $85 \%$. ${ }^{1}$ With increased survival rates, more survivors need scheduled surveillance programmes for detection of possible late effects as well as screening for relapse of ALL or second malignant neoplasm (SMN). ALL survivors are known to have more chronic conditions (late effects) than their general population peers and to have increased use of both primary and secondary health care services after end of treatment. ${ }^{2-14}$ Studies examining the occurrence of late effects have contributed with important knowledge to follow-up programmes. However, to the best of our knowledge, no studies have investigated the use of health care before a relapse or an SMN in survivors of childhood ALL.

Studies of health care use before a primary diagnosis of childhood ALL have revealed increased health care use 2-3 months before 
the diagnosis, thus reflecting a short period of symptoms. ${ }^{1516}$ Adolescents and young adults are found to have a longer interval with increased primary health care use for 5-6 months before primary diagnosis. ${ }^{17}$ Earlier studies indicate that the increased primary health care use could have a bimodal structure with the first peak 10-12 months before the primary diagnosis. ${ }^{15}$

Health care utilisation may reflect both the duration of symptoms before the diagnosis is established and the sectorial distribution of used care associated with these symptoms. Considerable focus is devoted to follow-up strategies for this group, and knowledge about the duration of increased health care use and the sectorial distribution of patients' help-seeking behaviour is therefore highly relevant. To address this knowledge gap, we aimed to analyse health care utilisation in general practice and

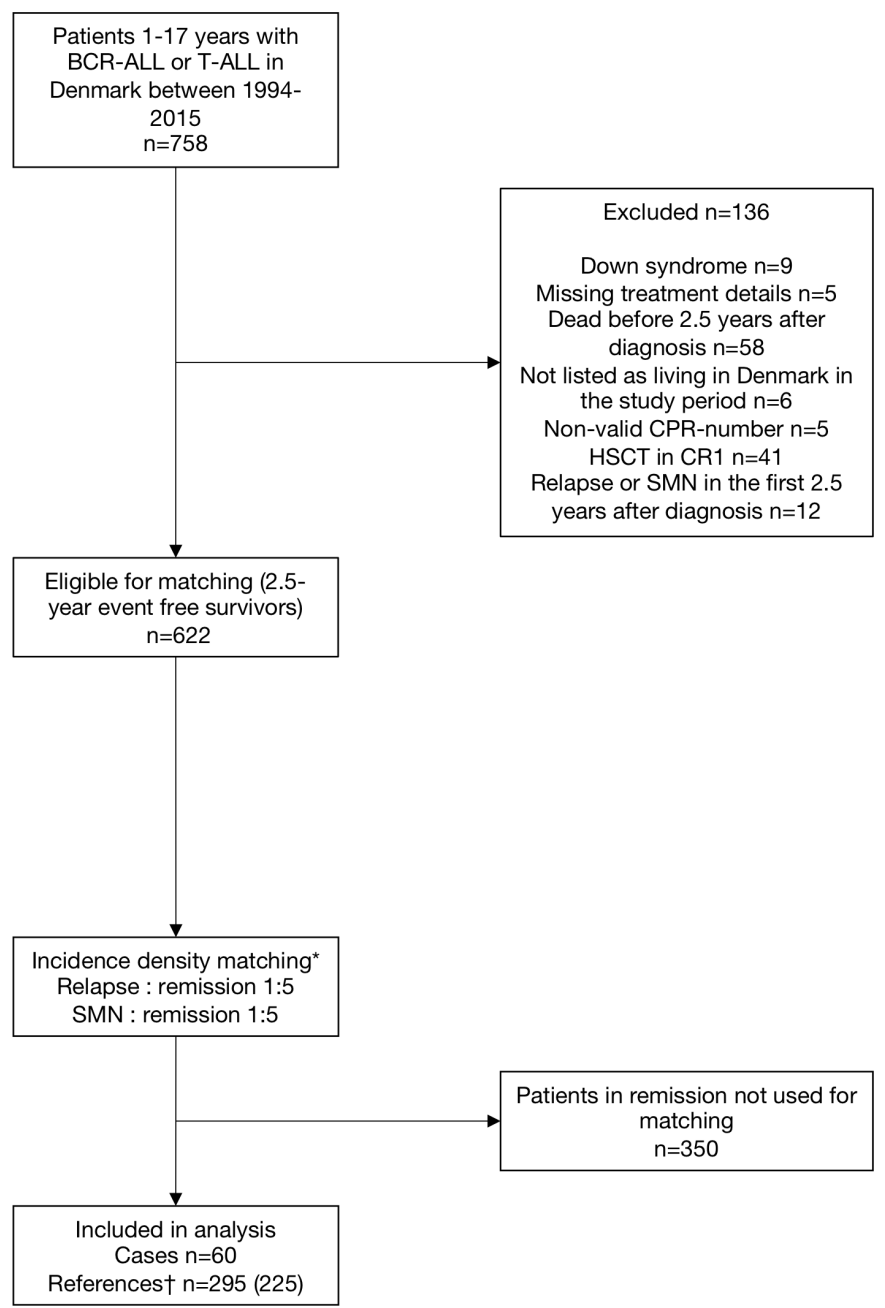

Figure 1 Flow diagram of the study population. Children with relapse/SMN and matched references in first remission. *Matching on age group, sex, risk group and treatment protocol. †The number in brackets is the number of unique persons - the same child can serve as a control more than once and controls can later become cases. BCR-ALL or T-ALL, B-cell precursor or T-lineage acute lymphoblastic leukaemia; CPR number, civil personal registration number; HSCT in CR1, haematopoietic stem cell transplantation in first complete remission; SMN, second malignant neoplasm. hospital during the 6-month period preceding a relapse or an SMN in survivors of childhood ALL.

\section{METHODS}

\section{Study design and setting}

This study is a nationwide, population-based, matched cohort study linking information from several Danish registries. We followed the RECORD guidelines for reporting of studies conducted using observational, routinely collected health data ${ }^{18}$ (online supplemental table S1).

In Denmark, the healthcare system is tax financed and free and equally available to all residents (population 5.8 million). All children in Denmark developing ALL are treated in this tax-financed system ensuring that the study is population based. After ALL treatment cessation, children in Denmark are followed in hospital-based outpatient surveillance programmes; visits are scheduled 6-12 times the first year, 4-6 times the second year and 1-3 times a year the following years. ${ }^{19}$ There are no scheduled visits in general practice.

All Danish citizens are assigned a unique identifier, the civil personal registration (CPR) number. The CPR number follows every resident from birth to death; data extracted from Danish public registries were linked on an individual level using the CPR number.

\section{Participants}

Eligible subjects were patients (1.0-17.9 years) diagnosed with non-infant B-cell precursor or T-lineage ALL between 1994 and 2015 and treated according to three consecutive Nordic Society of Pediatric Hematology and Oncology (NOPHO) trials: the ALL1992, ALL2000 and ALL2008 trials. ${ }^{120}$ Participants were identified in the Danish part of the NOPHO ALL registry. Cases were defined as childhood ALL survivors having a relapse or an SMN as the first event 2.5 years or more after primary diagnosis and before December 2017. Cases were matched 1:5 with childhood ALL survivors still in first remission with the same sex, age group (under 10 years or 10 years or more), NOPHO treatment protocol (ALL1992, ALL2000 or ALL2008) and risk group (high-risk or non-high-risk) (see flow chart, figure 1). Matching was based on incidence density sampling using the Stata command, sttocc. Due to the population-based design, the study sample size was determined by the number of cases in the area during the study period and no sample size calculation was performed.

\section{Data sources and variables}

Data were extracted from nationwide registries (table 1) and hosted by Statistics Denmark. Authors had access to a de-identified data output. Data on health care utilisation were extracted for the period 1 January 1997 to 31 December 2017. A relapse is defined as the reoccurrence of ALL after complete remission; a relapse can occur as an isolated bone marrow relapse, an isolated 
Table 1 Data sources and variables

\begin{tabular}{|c|c|c|}
\hline & Registries & Variables \\
\hline \multicolumn{3}{|l|}{ Exposures } \\
\hline & NOPHO ALL Registry ${ }^{* 120}$ & $\begin{array}{l}\text { Relapse of ALL } \\
\text { First remission }\end{array}$ \\
\hline & Danish Cancer Registry ${ }^{25}$ & Second malignant neoplasm \\
\hline \multicolumn{3}{|l|}{ Outcomes } \\
\hline Secondary health care & Danish National Patient Registry§ $\S^{26}$ & $\begin{array}{l}\text { Contacts to public and private hospitals: } \\
\text { Inpatient hospitalisations } \\
\text { Outpatient visits }\end{array}$ \\
\hline \multicolumn{3}{|l|}{ Covariates } \\
\hline & Danish Civil Registration System ${ }^{27}$ & $\begin{array}{l}\text { Sex } \\
\text { Age } \\
\text { Vital status } \\
\text { Immigration } \\
\text { Emigration }\end{array}$ \\
\hline
\end{tabular}

*NOPHO ALL Registry, Nordic Society of Paediatric Haematology and Oncology ALL Registry. The registry holds data on all children aged 1.0-14.9 years in Denmark diagnosed with ALL since 1992. From 2008 and onwards, the ALL Registry was extended to include children and adolescents aged $1.0-17.9$ years.

†The Danish Cancer Registry holds information on all new cases of cancer in Denmark.

$\ddagger$ The National Health Insurance Service Register holds information on all contacts to general practice in Denmark. The following contacts were excluded: preventive health examination of children, vaccinations, screening for cervical cancer and pregnancy care. For a complete list of codes, see online supplemental table S2.

$\S$ The Danish National Patient Registry holds information on all contacts to public and private hospitals. The following contacts were excluded: visits to the accident and emergency department.

ALL, acute lymphoblastic leukaemia.

extramedullary relapse (eg. the central nervous system or testis) or a combined bone marrow and extramedullary relapse. SMN is defined as the occurrence of a new malignant neoplasm. Survivors of ALL are at increased risk of developing a new malignant neoplasm compared with population peers; other haematological malignancies and tumours of the central nervous system are the most common types of SMNs. ${ }^{21}$

\section{Statistical methods}

The index date was the date of event (relapse or SMN) for cases. The corresponding index date for references was defined as the date with the same interval from the primary diagnosis as for the case. For all included individuals, follow-up started no earlier than 2.5 years after diagnosis to ensure that treatment had ended and remission reached. Health care utilisation was assessed from 6 months before the index date/event.

The monthly rates for primary health care contacts (daytime contacts, out-of-hours contacts and diagnostic procedures) and hospital contacts (inpatient hospitalisations and hospital outpatient contact) were calculated as crude estimates for each of the 6 months preceding the 
index date. Negative binominal regression models were used to calculate incidence rate ratios (IRRs) to compare monthly rates of contacts between cases and references. Cluster robust variance estimation was applied to account for possible cluster effects at patient level. This was relevant as measurements on the same person were repeated monthly.

Estimates of IRRs were adjusted for sex, age and time since diagnosis. To adjust for age and time since diagnosis, we used restricted cubic splines with six knots to allow for a non-linear relationship. Furthermore, we performed analyses restricted to cases developing a relapse and to their references. All estimates are presented with 95\% CIs. All tests were two-sided and a $p$ value $\leq 0.05$ was considered statistically significant. Data were analysed using the statistical software Stata V.16.1 (StataCorp LLC, College Station, Texas, USA).

\section{Patient and public involvement}

The study included no patient and public involvement.

\section{RESULTS}

\section{Patient characteristics}

The study included 60 cases and 295 references; 49 $(81.7 \%)$ of the 60 cases suffered a relapse and $11(18.3 \%)$ an SMN (table 2). In two cases, there were fewer than five matching references.

\section{Health care utilisation}

We found a mean of 0.73 (95\% CI 0.53 to 1.02) daytime general practice visits during the month before the event in cases corresponding to an IRR of 2.71 (95\% CI 1.71 to 4.28). For the month before the event, we found an IRR of 8.12 (95\% CI 3.01 to 21.86) for general practice out-ofhours contacts and an IRR of 5.89 (95\% CI 2.44 to 14.21) for diagnostic procedures in general practice (figure 2). For daytime general practice visits, data suggest a possible bimodal structure with increased IRRs during 4-6 months before the event.

For cases, hospital utilisation was 3.42 (95\% CI 2.83 to 4.12) contacts in the last month before the event compared with 0.72 (95\% CI 0.61 to 0.85 ) contacts for references, corresponding to an IRR of 5.01 (95\% CI 3.78 to 6.63) the month before the event. For the second-last month before the event, we found an IRR of 1.94 (95\% CI 1.32 to 2.85 ) (figure 3 ).

In analyses restricted to cases developing a relapse, hospital utilisation also increased 2 months before the event (significantly increased only 1 month before the event). In general practice, data continued to suggest a bimodal structure (figure 4).

\section{DISCUSSION}

The present national, population-based matched cohort study shows that utilisation of general practice and hospital services increased significantly 2 months before
Table 2 Characteristics of the study population

\begin{tabular}{|c|c|c|}
\hline Characteristic & $\begin{array}{l}\text { Cases* } \\
\mathrm{N}=60\end{array}$ & $\begin{array}{l}\text { References } \uparrow \\
\mathrm{N}=295\end{array}$ \\
\hline \multicolumn{3}{|l|}{ Sex, n (\%) } \\
\hline Male & 38 (63.3) & $190(64.4)$ \\
\hline Female & $22(36.7)$ & 105 (35.6) \\
\hline $\begin{array}{l}\text { Median age at index } \\
\text { datef (IQI) }\end{array}$ & $11.3(8.4-16.1)$ & $11.1(7.7-15.7)$ \\
\hline \multicolumn{3}{|l|}{$\begin{array}{l}\text { Age group at index date, } \\
\mathrm{n}(\%)\end{array}$} \\
\hline Age $<10$ years & $21(35.0)$ & $130(44.1)$ \\
\hline Age $\geq 10$ years & $39(65.0)$ & $165(55.9)$ \\
\hline \multicolumn{3}{|l|}{ Treatment protocol, n (\%) } \\
\hline NOPHO ALL1992 & $24(40.0)$ & $120(40.7)$ \\
\hline NOPHO ALL2000 & $22(36.7)$ & 105 (35.6) \\
\hline NOPHO ALL2008 & $14(23.3)$ & $70(23.7)$ \\
\hline \multicolumn{3}{|l|}{ Cell line, n (\%) } \\
\hline B-precursor ALL & $55(91.7)$ & $253(85.8)$ \\
\hline T-ALL & $5(8.3)$ & $42(14.2)$ \\
\hline \multicolumn{3}{|l|}{ Risk group, n (\%) } \\
\hline Non-high-risk & $46(76.7)$ & $230(78.0)$ \\
\hline High-risk & $14(23.3)$ & $65(22.0)$ \\
\hline $\begin{array}{l}\text { Median time from } \\
\text { diagnosis to index date } \\
\text { (years, IQI) }\end{array}$ & $3.8(3.2-5.1)$ & $3.8(3.2-5.1)$ \\
\hline \multicolumn{3}{|l|}{ Type of event, n (\%) } \\
\hline Relapse & $49(81.7)$ & - \\
\hline SMN & $11(18.3)$ & - \\
\hline
\end{tabular}

${ }^{*}$ Cases, survivors of childhood ALL developing a relapse or an SMN as the first event.

†References, survivors of childhood ALL still in first remission matched on age, sex, treatment protocol and risk group. flndex date, the date of event for cases and the corresponding date for references.

ALL, acute lymphoblastic leukaemia; IQI, interquartile interval; NOPHO, Nordic Society of Paediatric Haematology and Oncology; SMN, second malignant neoplasm.

the diagnosis of a relapse or an SMN compared with references still in first remission. Our data showed a possible bimodal structure for daytime consultations in general practice in general and for cases developing a relapse more pronounced, with increased utilisation 5-6 months before relapse. This indicates that there could be early warnings. The increased use of hospital health care services the last month before relapse is most likely explained by the diagnostic workup.

\section{Strengths and limitations}

The population-based design with use of nationwide registries linked on an individual level is a strength. This ensured optimal completeness of data and follow-up. However, a relapse diagnosis is not 

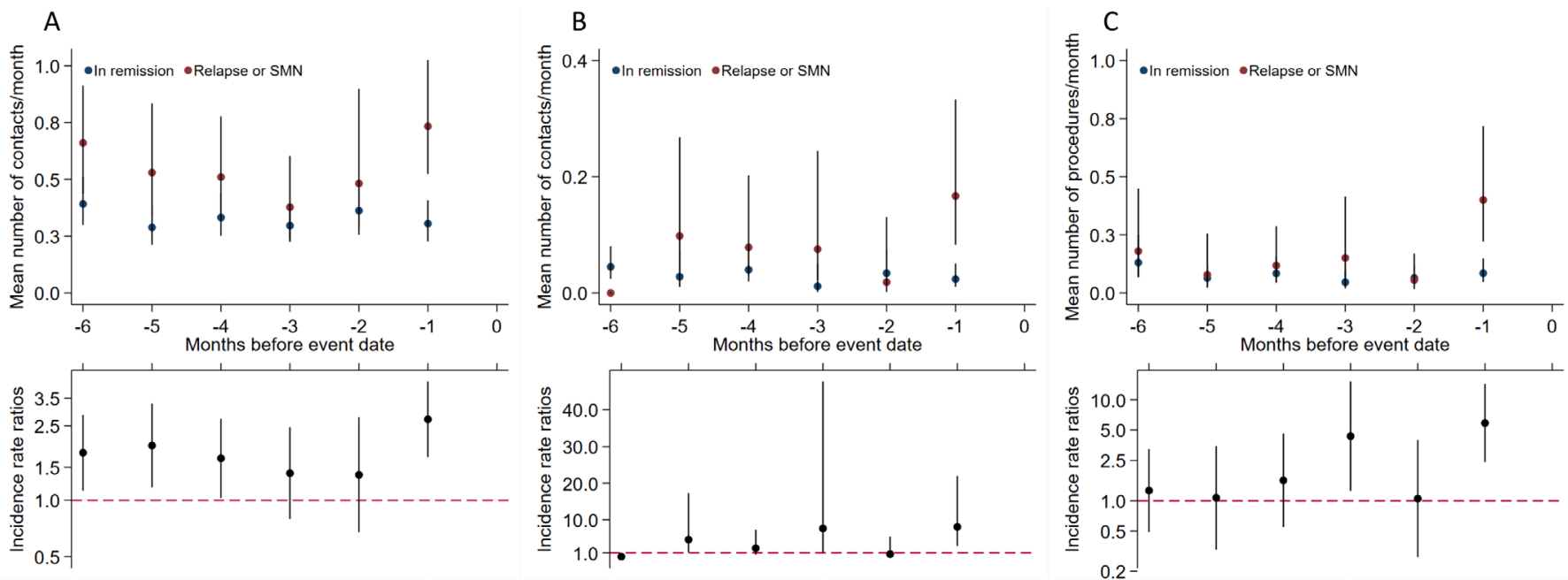

Figure 2 General practice health care utilisation. General practice utilisation by months before event for cases* $(n=60)$ compared with references $\uparrow(n=295)$. (A) Daytime. (B) Out-of-hours. (C) Diagnostic procedures. Top panel: contacts/diagnostic procedure mean rates per month presented as crude rates. Bottom panel: incidence rate ratios adjusted for age, sex and time since diagnosis. Vertical lines represent $95 \%$ Cls. ${ }^{*}$ Cases, survivors of childhood ALL developing a relapse or an SMN as the first event. †References, survivors of childhood ALL still in first remission matched on age, sex, treatment protocol and risk group. ALL, acute lymphoblastic leukaemia; SNM, second malignant neoplasm.
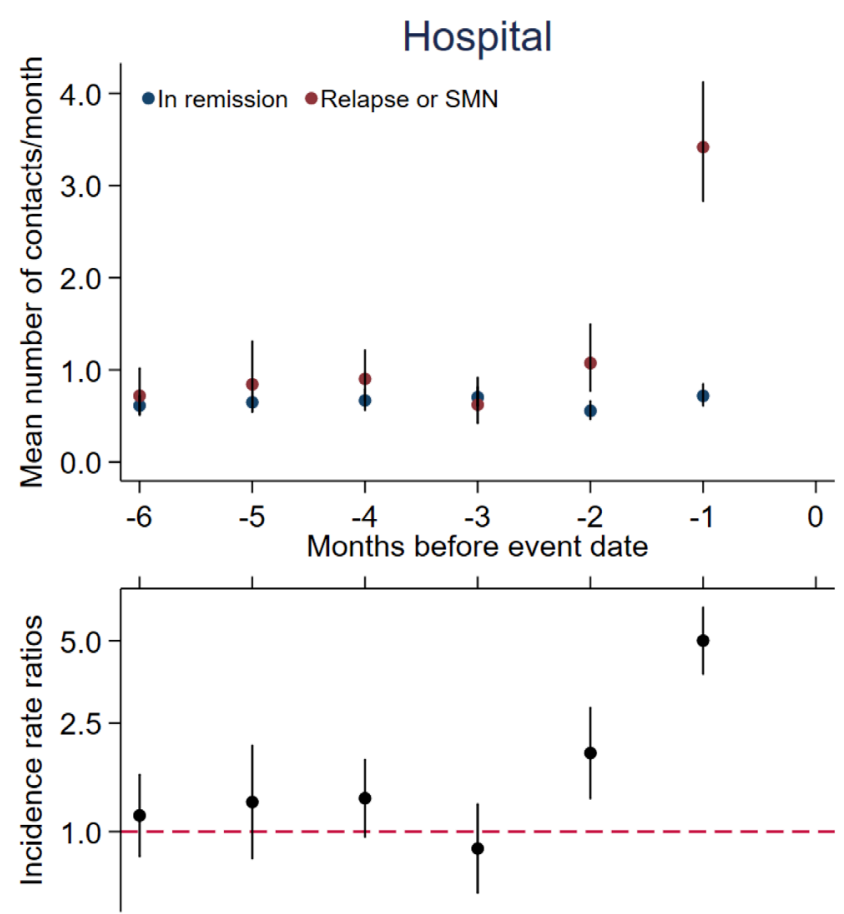

Figure 3 Hospital health care utilisation. Hospital health care utilisation by months before event for cases ${ }^{*}(n=60)$ compared with references $\dagger(n=295)$. Top panel: contacts mean rates per month presented as crude rates. Bottom panel: incidence rate ratios adjusted for age, sex and time since diagnosis. Vertical lines represent $95 \%$ Cls. *Cases, survivors of childhood ALL developing a relapse or an SMN as the first event. †References, survivors of childhood ALL still in first remission matched on age, sex, treatment protocol and risk group. ALL, acute lymphoblastic leukaemia; SMN, second malignant neoplasm. registered in the Danish Cancer Registry. Therefore, data on relapses were collected from the NOPHO ALL registry. ${ }^{120}$ The NOPHO ALL registry is a very robust data source as it is updated regularly by research nurses and paediatric oncologists. Nevertheless, the registry might not contain data on all relapses that occur after patients leave a paediatric department. Children with a relapse that was unregistered would belong to the reference group, which could lead to bias towards underestimating relapse frequency and the differences in use of health care services.

Electronic outcome data are collected routinely and uniformly in the Danish healthcare system. Data were collected for remuneration and not for the purpose of the present study. Potential misclassification of outcomes is expected to be equally distributed among cases and references, and any such misclassification is expected to be non-differential. ${ }^{22}$

The relatively small case group in our study is a limitation, leading to a low statistical precision with broad CIs. Another limitation is the absence of information regarding the motivations for contacts to the healthcare system as this information is not available in the National Health Insurance Service Register. ${ }^{23}$

We compared periods with the same interval from diagnosis in cases and references as previous research has shown that time since diagnosis affects utilisation of health care. ${ }^{89}$ We made an effort to reduce confounding by age, gender, calendar period and treatment regime by matching cases with references. We had no information on the amount and type of late effects and we were thus not able to match by late effects. However, previous studies suggest that the types of late effects have changed over calendar 

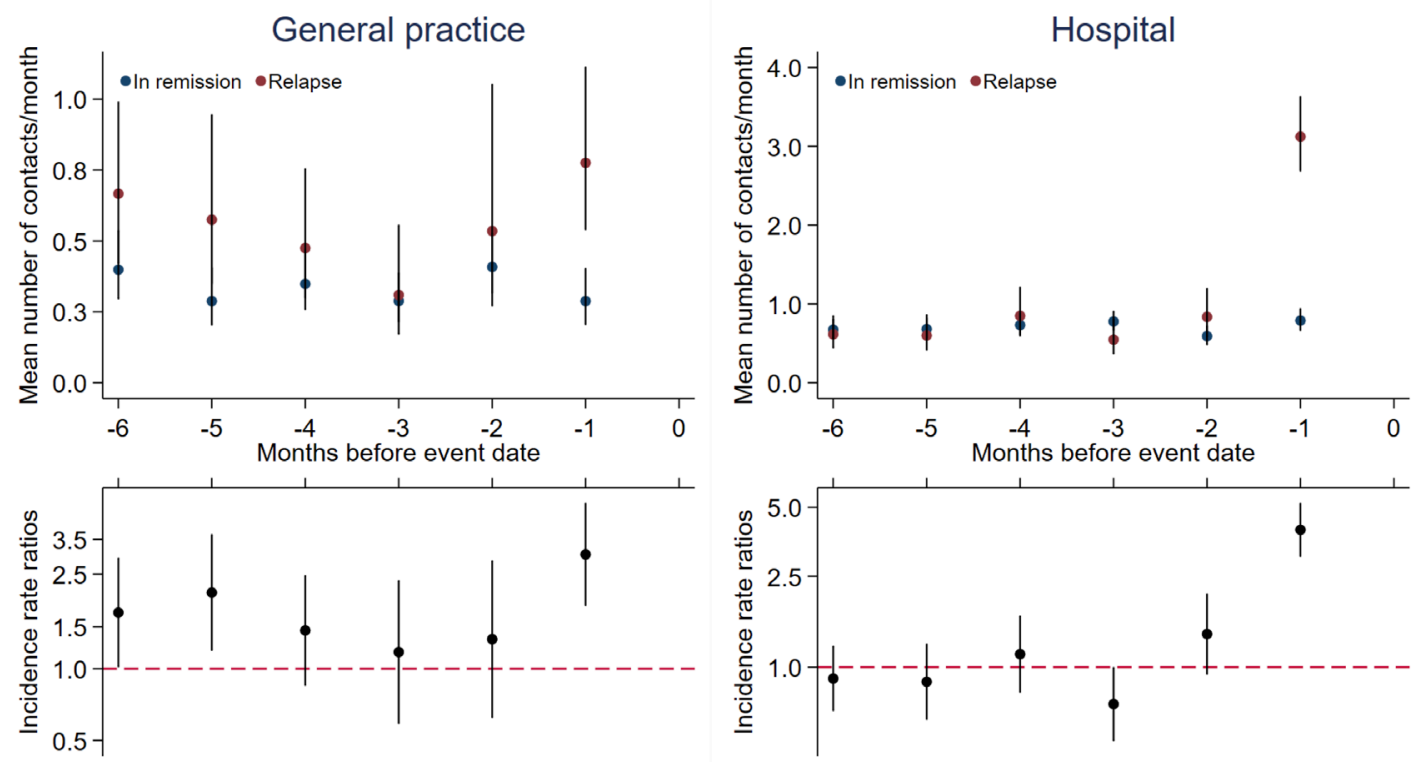

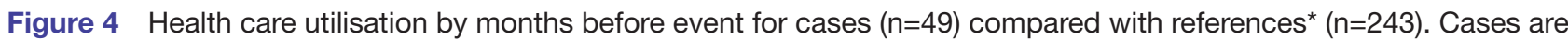
survivors of childhood ALL developing a relapse as the first event (cases developing an SMN are excluded in this analysis). Top panel: contacts mean rates per month presented as crude rates. Bottom panel: incidence rate ratios adjusted for age, sex and time since diagnosis. Vertical lines represent $95 \%$ Cls. ${ }^{*}$ References, survivors of childhood ALL still in first remission matched on age, sex, treatment protocol and risk group. ALL, acute lymphoblastic leukaemia; SMN, second malignant neoplasm.

time making it relevant to match on treatment era (protocol) ${ }^{6}$

We were not able to adjust for sociodemographic factors and unmeasured confounding could thus be present. We expect potential bias to be negligible, and we believe that our findings can be generalised to other countries with comparable healthcare systems.

\section{Comparison with existing literature}

Previous studies on health care utilisation in ALL survivors have found increased use of primary and secondary health care after end of treatment. ${ }^{2-14}$ However, previous studies did not evaluate health care use before a relapse or an SMN. Studies on health care utilisation before primary ALL diagnosis in childhood found increased use of health care 2-3 months before the primary diagnosis ${ }^{15}{ }^{16}$; and based on these findings, we expected a short duration of increased health care use. Furthermore, a bimodal structure for general practice health care use before the primary diagnosis is reported, but with the first peak 10-12 months before diagnosis. ${ }^{15}$

A recent study examining use of health care before a cancer recurrence or an SMN in adult cancer survivors reported increased use of health care up to a year before diagnosis among patients diagnosed with a wide range of solid tumours. ${ }^{24}$ Based on knowledge on health care use before a primary cancer, it is expected that patients with solid tumours have a longer interval of increased health care utilisation. ${ }^{15} 17$

\section{Conclusions}

Survivors of childhood ALL developing a relapse or an SMN when in remission had a higher use of general practice and hospital health care services compared with matched references, 1-2 months before the event. There was a possible bimodal structure for daytime visits to general practice with increased visits also 4-6 months before the event. As health care utilisation may be seen as a proxy for morbidity, this indicates that there could be early warnings. To the best of our knowledge, this is the first study to investigate use of health care before a relapse or an SMN in survivors of childhood ALL in remission, and further research is needed. If an increased use of general practice services up to 6 months before the diagnosis of a relapse or an SMN is confirmed in future research, there may be a window for earlier diagnosis. An increased knowledge of the patient pathway to relapse/ SMN diagnosis is important to ensure optimal organisation of surveillance programmes.

Author affiliations

${ }^{1}$ Department of Paediatrics and Adolescent Medicine, Aarhus University Hospital, Aarhus, Denmark

${ }^{2}$ Research Centre for Cancer Diagnosis in Primary Care, Research Unit for General Practice, Department of Public Health, Aarhus University, Aarhus, Denmark ${ }^{3}$ Department of Paediatrics and Adolescent Medicine, Copenhagen University Hospital, Copenhagen, Denmark

${ }^{4}$ Institute of Clinical Medicine, Faculty of Health and Medical Sciences, University of Copenhagen, Copenhagen, Denmark

${ }^{5}$ Department of Paediatrics and Adolescent Medicine, Aalborg University Hospital, Aalborg, Denmark

${ }^{6}$ Hans Christian Andersen Children's Hospital, Odense University Hospital, Odense, Denmark

Acknowledgements The authors wish to thank Kaare Rud Flarup for his assistance with data management.

Contributors KSJ designed the study, analysed and interpreted data and wrote the manuscript; BKA interpreted data and edited the manuscript; HS designed the study and edited the manuscript; AZF analysed and interpreted data and edited the manuscript; KS interpreted data and edited the manuscript; SR interpreted 
data and edited the manuscript; MTC interpreted data and edited the manuscript; PV designed the study, interpreted data and edited the manuscript. All authors approved the final manuscript.

Funding This work was supported by a grant from the Danish Cancer Society (Kræftens Bekæmpelse). Grant number R124-A7831-15-S2.

Disclaimer The funders had no role in the design and conduct of the study.

Competing interests BKA declares the following: sponsor for the investigator initiated NOR-GRASPALL 2016 study. KS declares the following: Speaker and/or Advisory Board Honoraria from Jazz Pharmaceuticals (2020) and Servier (2020); speaker fee from Amgen (2020) and Medscape (2020); Educational grant from Servier (2020).

Patient consent for publication Not required.

Ethics approval This study was approved by the Danish Data Protection Agency (ID 277). Medical ethical approval was not required according to Danish law.

Provenance and peer review Not commissioned; externally peer reviewed.

Data availability statement No data are available. Data sharing statement: According to the data agreement with the data provider, we are not allowed to share our data. Data are stored and maintained electronically at Statistics Denmark.

Supplemental material This content has been supplied by the author(s). It has not been vetted by BMJ Publishing Group Limited (BMJ) and may not have been peer-reviewed. Any opinions or recommendations discussed are solely those of the author(s) and are not endorsed by BMJ. BMJ disclaims all liability and responsibility arising from any reliance placed on the content. Where the content includes any translated material, BMJ does not warrant the accuracy and reliability of the translations (including but not limited to local regulations, clinical guidelines, terminology, drug names and drug dosages), and is not responsible for any error and/or omissions arising from translation and adaptation or otherwise.

Open access This is an open access article distributed in accordance with the Creative Commons Attribution Non Commercial (CC BY-NC 4.0) license, which permits others to distribute, remix, adapt, build upon this work non-commercially, and license their derivative works on different terms, provided the original work is properly cited, appropriate credit is given, any changes made indicated, and the use is non-commercial. See: http://creativecommons.org/licenses/by-nc/4.0/.

ORCID iD

Karen Schow Jensen http://orcid.org/0000-0002-0811-8818

\section{REFERENCES}

1 Toft N, Birgens H, Abrahamsson J, et al. Results of NOPHO ALL2008 treatment for patients aged $1-45$ years with acute lymphoblastic leukemia. Leukemia 2018;32:606-15.

2 de Fine Licht S, Rugbjerg K, Gudmundsdottir T, et al. Long-term inpatient disease burden in the Adult Life after Childhood Cancer in Scandinavia (ALiCCS) study: a cohort study of 21,297 childhood cancer survivors. PLoS Med 2017;14:e1002296.

3 Font-Gonzalez A, Feijen ELAM, Geskus RB, et al. Risk and associated risk factors of hospitalization for specific health problems over time in childhood cancer survivors: a medical record linkage study. Cancer Med 2017;6:1123-34.

4 Sieswerda E, Font-Gonzalez A, Reitsma JB, et al. High hospitalization rates in survivors of childhood cancer: a longitudinal follow-up study using medical record linkage. PLoS One 2016;11:e0159518.

5 Sørensen GV, Winther JF, de Fine Licht S, et al. Long-term risk of hospitalization among five-year survivors of childhood leukemia in the Nordic countries. J Natl Cancer Inst 2019;111:943-51.
6 Mulrooney DA, Hyun G, Ness KK, et al. The changing burden of longterm health outcomes in survivors of childhood acute lymphoblastic leukaemia: a retrospective analysis of the St Jude Lifetime Cohort Study. Lancet Haematol 2019;6:e306-16.

7 Bhakta N, Liu Q, Ness KK, et al. The cumulative burden of surviving childhood cancer: an initial report from the St Jude Lifetime Cohort Study (SJLIFE). Lancet 2017;390:2569-82.

8 Heins MJ, Lorenzi MF, Korevaar JC, et al. Non-oncology physician visits after diagnosis of cancer in adolescents and young adults. $J$ Cancer Surviv 2016;10:783-8.

9 Heins MJ, Lorenzi MF, Korevaar JC, et al. Non-oncology physician visits after diagnosis of cancer in children. BMC Fam Pract 2016;17:60.

10 Rebholz CE, Reulen RC, Toogood AA, et al. Health care use of longterm survivors of childhood cancer: the British Childhood Cancer Survivor Study. J Clin Oncol 2011;29:4181-8.

11 Shaw AK, Pogany L, Speechley KN, et al. Use of health care services by survivors of childhood and adolescent cancer in Canada. Cancer 2006;106:1829-37.

12 Oeffinger KC, Mertens AC, Hudson MM, et al. Health care of young adult survivors of childhood cancer: a report from the Childhood Cancer Survivor Study. Ann Fam Med 2004;2:61-70.

13 Streefkerk N, Heins MJ, Teepen JC, et al. The involvement of primary care physicians in care for childhood cancer survivors. Pediatr Blood Cancer 2019;66:e27774.

14 McBride ML, Lorenzi MF, Page J, et al. Patterns of physician follow-up among young cancer survivors: report of the Childhood, Adolescent, and Young Adult Cancer Survivors (CAYACS) research program. Can Fam Physician 2011;57:e482-90.

15 Ahrensberg JM, Fenger-Grøn M, Vedsted P. Use of primary care during the year before childhood cancer diagnosis: a nationwide population-based matched comparative study. PLoS One 2013;8:e59098.

16 Yang TO, Liu Y-L, Huang W-T, et al. Specific and non-specific clinical presentations in the year before the diagnosis of childhood leukaemia. Pediatr Blood Cancer 2016;63:1387-93.

17 Ahrensberg JM, Fenger-Grøn M, Vedsted P. Primary care use before cancer diagnosis in adolescents and young adults - a nationwide register study. PLoS One 2016;11:e0155933.

18 Benchimol El, Smeeth L, Guttmann A, et al. The REporting of studies Conducted using Observational Routinely-collected health Data (RECORD) statement. PLoS Med 2015;12:e1001885.

19 Jensen KS, Oskarsson T, Lähteenmäki PM, et al. Detection mode of childhood acute lymphoblastic leukaemia relapse and its effect on survival: a Nordic population-based cohort study. Br J Haematol 2021. doi:10.1111/bjh.17555. [Epub ahead of print: 27 May 2021] (published Online First: 2021/05/28).

20 Schmiegelow K, Forestier E, Hellebostad M, et al. Long-term results of NOPHO ALL-92 and ALL-2000 studies of childhood acute lymphoblastic leukemia. Leukemia 2010;24:345-54.

21 Schmiegelow K, Levinsen MF, Attarbaschi A, et al. Second malignant neoplasms after treatment of childhood acute lymphoblastic leukemia. J Clin Oncol 2013;31:2469-76.

22 Erlangsen A, Fedyszyn I. Danish nationwide registers for public health and health-related research. Scand J Public Health 2015;43:333-9.

23 Andersen JS, Olivarius NDF, Krasnik A. The Danish National Health Service Register. Scand J Public Health 2011;39:34-7.

24 Rasmussen LA, Jensen H, Virgilsen LF, et al. Healthcare utilisation in general practice and hospitals in the year preceding a diagnosis of cancer recurrence or second primary cancer: a population-based register study. BMC Health Serv Res 2019;19:941.

25 Gjerstorff ML. The Danish Cancer Registry. Scand J Public Health 2011;39:42-5.

26 Lynge E, Sandegaard JL, Rebolj M. The Danish National Patient Register. Scand J Public Health 2011;39:30-3.

27 Schmidt M, Pedersen L, Sørensen HT. The Danish Civil Registration System as a tool in epidemiology. Eur J Epidemiol 2014;29:541-9. 